\title{
Application of Queuing Theory to a Bank's Automated Teller Machine (ATM) Service Optimization
}

\author{
Ogunlade Temitope Olu \\ Department of Mathematics, Ekiti State University, Ado-Ekiti, Nigeria \\ Email address: \\ topsmatic@gmail.com

\section{To cite this article:} \\ Ogunlade Temitope Olu. Application of Queuing Theory to a Bank's Automated Teller Machine (ATM) Service Optimization. Mathematics \\ Letters. Vol. 5, No. 1, 2019, pp. 8-12. doi: 10.11648/j.ml.20190501.12
}

Received: April 16, 2019; Accepted: May 29, 2019; Published: June 24, 2019

\begin{abstract}
Automated teller machine (ATM) is one of the several electronic banking channels used in the banking industry. This brought about queue (waiting line) and this is because customers waiting in line to receive service by using the ATM are inevitable and hence queue control became an issue This paper applies queuing theory to determine the average time customers spend on queue and actual time of delivery thereby examining the impact of time wasting and cost associated with it. Direct non-participatory observation and questionnaire were engaged to record time measurements and primary data. Performance measure of the system was calculated and the number of servers for optimum service delivery was also analysed. To analyse customers' satisfaction, questionnaires were administered to ATM customers. Respondents fairly represent the ATM customer population, males and females, old and young and persons from various occupation backgrounds. Responses from above are analyzed as answers to questions, presented on the questionnaire. For each question, we analyzed using incidences and percentage to determine the weight of support for a particular option. Means, variances and standard derivation are computed for questions on tolerable waiting time and average cash withdrawal. It was commended that the case bank increase the number of servers so as to help reduce wait time and wait cost. From the analysis and observation, service unavailability was observed to be a contributory factor to queue formation at the case ATM.
\end{abstract}

Keywords: Queueing Theory, Waiting Time, Service Time, Optimum Service, Performance Measure

\section{Introduction}

Electronic banking is one of the several successes of technology in the banking world. Automated teller machine (ATM) is one of the several electronic banking channels used in the banking industry. ATM is among the most important service facilities in the banking industry [1]. In Nigeria, ATM as a banking instrument appeared in 1989 and has employed wide spread acceptance and usage. In a survey conducted by a study, more than half of respondents revealed their preference for ATM as conducting transactions [2]. But unfortunately, this brought about queue (waiting line) and this is because customers waiting in line to receive service in any service system are inevitable and hence queue control became an issue. ATMs themselves have as a result become subjects of large service demands which directly translate to queue for services when these demands cannot be quickly satisfied. The situation becomes compounded during festive periods and month endings, around which time demand for cash is high. So to control this situation, queuing theory was introduced.

Queuing theory is also known as the theory of congestion; it is the branch of operational research that explores the relationship between the demand on a service system and the delays suffered by the users of that system [3-5]. Other researchers [6-11] have worked on improving service inside the banking hall.

Research on queuing theory application in banking operations can be said to be at the budding stage with noticeable studies undertaken in these studies [12-14]. The study [12] explored ways to improve the efficiency of Chinese commercial banks in relation to customer queuing in bank halls. Emphasis was on the investigation of the queue problem by way of queue theory and based on assumed data (arrival rate $=32$ and service rate $=20$ ). A connection can be established between the work of the study [12] and this research in terms of the core object of controlling queues. However, their work focuses mainly on queue development 
of unmanaged interactions between customers and bank counters in bank halls but this research captures customers service time and the average of the service times used to analyses its sensitivity to the queue formation at the case ATM. The study [13] explored the service efficiency of ATMs of twenty six (26) banking institutions (including postal banking services) in Taiwan in a related studies. A designed experiment is used to collect service time data on ATMs functions composed of cash of cash withdrawal, fund transferring, password change and balance enquiry. Relying on the available data, they utilized the appropriate queue model to arrive at most efficient and least efficient banks in Taiwan in terms of specified performance parameters such as how long customers stay in the service system. Lin and Yang's work focal point was a comparative study of ATM service efficiency of the banks involved in terms of predefined performance indicators.

In a study [14], three ATM facilities of three different banks at Veliore Institute of Technology (V. I. T) were studied by applying simulation and queuing theory to collected data. Data collection achieved through simulation was done on a weekday free period and on weekends. They performed computations on converted data to find the waiting time of customer in queue and in system based upon which they compared customer satisfaction level with the service provided by the various ATM facilities. Solution arrived at by the study [14] are achieved on relatively small data (maximum of 20 customers observations per period). In the study [15] a methodology to calculate queue length and waiting time utilizing gateway server information was devised. The relevant queue models are applied in the estimate of queue length which is then used to estimate the memory size of gateway servers.

ATM and ATM queue are a recent development in Nigeria banking system. The major concern is the erratic nature of ATM queues. Banks are confronted with long queues during busy periods (most especially during festive periods and months ending around which time most public workers are paid).

In this study we investigate the number of servers needed for optimum service delivery at Heritage Bank, Ekiti State University branch Ado-Ekiti, Nigeria, which presently has two ATMs. So this study is required to investigate the expected waiting time of customers and the actual waiting time in banks, where the gaps between the actual and expected waiting time can be analyzed to know how to improve on the efficiency and effectiveness of their bank. Such problems; how poor service facilities has affected the overall bank performance, how service facilities has affected the time of customers. How poor service's delivery has affected customers behavior.

\section{Materials and Methods}

To formulate a model for this system, various assumptions were put into consideration. The arrival of customers into the system is discrete from Poisson distribution with arrival rate $\lambda$, the queuing discipline is first come first serve, the service channel can only render service of finite rate exponentially distribution with service rate, $\mu$, the calling population (i.e. the number of customers calling for service is finite), the number of servers is $\mathrm{C}$ and the number of customer in the system at the time of initiating the observation is assumed to have arrived in the first unit time.

The waiting area for the customers in the system is infinite, that is unlimited. Hence, with the above assumptions and approach, the formulated model $\mathrm{M}|\mathrm{M}| \mathrm{C}$ by Kendall's notation, [16].

$$
\lambda_{n}=\lambda, \mu_{n}=\left\{\begin{array}{c}
n \mu \text { if } n=0,1, \ldots, c \text { i.e. } n \leq c \\
c \mu \text { if } n=c+1, c+2 \text { i.e } n \geq c
\end{array}\right.
$$

The probability of zero customers in the system $\left(P_{0}\right)$ and the probability of $\mathrm{n}$ customer in the system $\left(P_{0}\right)$ are given by:

$$
P_{0}=\left\{\frac{\left(\frac{\lambda}{\mu}\right)^{c}}{c !\left[1-\frac{\lambda / \mu}{c}\right]}+\frac{(\lambda / \mu)^{1}}{1 !}+\frac{(\lambda / \mu)^{2}}{2 !}+\cdots+\frac{(\lambda / \mu)^{c-1}}{(c-1) !}\right\}^{-1}
$$

The capacity utilization in this system is $\lambda / c \mu$.

If $\frac{\lambda}{c \mu}>1$, then the waiting line grows larger and larger i.e. becomes infinite if the process runs long enough.

With $\mathrm{C}$ service facilities, the average number of customers in the queue is.

$$
N_{q}=\frac{\left(\frac{\lambda}{\mu}\right)^{c+1} P_{0}}{C . C !\left[1-\frac{\lambda / \mu}{C}\right]^{2}}
$$

The average number in the system is.

$$
N_{s}=N_{q}+\frac{\lambda}{\mu}
$$

Expected waiting time in the queue for an arrival is.

$$
T_{q}=\frac{N_{q}}{\lambda}
$$

The expected total time spent in the system is.

$$
T=\frac{N_{S}}{\lambda}
$$

\section{Results and Discussion}

The case bank operates two automated teller machines. In an 8- hour's period of observation, over the study period, an average 90 customers arrive at the terminal on a daily basis. Above 59 constituting $65 \%$ of arrivals get the opportunity to perform transactions. Service unavailability is a major contribution factor that denies about $35 \%$ of customers who arrive at the Centre the opportunity to perform some cash related transaction. In such a situation, both ATMS are not available for service.

From the data collected at the bank inter - arrival time for 191 customers, $T=1315$ minutes.

Time taken by 191 customers to be served, $\mathrm{S}=1585$ 
minutes.

Now, the.

Arrival rate, $\lambda=\frac{N}{T}=\frac{191}{1315}=0.1452$.

Service rate, $\mu=\frac{N}{S}=\frac{191}{1585}=0.1205$.

Traffic intensity, $\rho=\frac{\lambda}{\mu}=\frac{0.1452}{0.1205}=1.2050$.

This implies that, $\lambda=0.1452$.

Hence utilization rate.

$$
\rho=\frac{\lambda}{2 \mu}=\frac{0.1452}{2(0.1205)}=0.6025
$$

Average number of customers in the queue.

$$
N_{q}=\frac{2 \rho^{3}}{1-\rho^{2}}=\frac{2(0.6025)^{3}}{1-(0.6025)^{2}}=\frac{0.4374}{0.6369}=0.6867
$$

Average number of customers in the system.

$$
N_{s}=\frac{2 \rho}{1-\rho^{2}}=\frac{2(0.6025)}{1-(0.6025)^{2}}=\frac{1.205}{0.6370}=1.8917
$$

Expected waiting time in queue.

$$
\begin{aligned}
T_{q}=\frac{\rho^{2}}{\mu\left(1-\rho^{2}\right)} & =\frac{(0.6025)}{0.1205\left(1-(0.6025)^{2}\right)}=\frac{0.3630}{0.0761} \\
& =4.7291
\end{aligned}
$$

Expected total time spent in the system.

$$
\begin{aligned}
T_{s}=\frac{1}{\mu\left(1-\rho^{2}\right)} & =\frac{1}{0.1205\left(1-(0.6025)^{2}\right)}=\frac{1}{0.076757} \\
& =13.0280
\end{aligned}
$$

\subsection{Customers' Satisfaction}

During the course of the study, 106 questionnaires were administered to ATM customers. Respondents fairly represent the ATM customer population, males and females, old and young and persons from various occupation backgrounds. Responses from above are analyzed as answers to questions, presented on the questionnaire. For each question, we analyzed using incidences and percentage to determine the weight of support for a particular option. Means, variances and standard derivation are computed for questions on tolerable waiting time and average cash withdrawal.

On average, customers felt that approximately eight (8) minutes was on acceptable time to wait. However as acceptable waiting responses were based on individual perspectives, description of what constitutes an acceptable waiting time tend to be around the interval one to five minutes. Most respondents felt that a waiting time of one five minutes was a reasonable time to wait.

Over fifty two percentage $(52 \%)$ of customers specified one to five minutes in their definition of acceptable waiting time. The standard derivation of the mean acceptable waiting time is 7.32 and a variance 53.34. Beyond the acceptable waiting time threshold, there is no guarantee of customers been patient to wait and perform transactions of particular interest. A customer may renege after thus time period; accruing to the bank as lost profit from lost business. Thus loss of business may occur immediately because the customer grows impatient and leaves or in the future, because the customer is sufficiently irritated that he or she does not come again.

The daily cash withdrawal limit at the case bank is $\$ 150,000$. About $92.5 \%$ of cash withdrawals at the ATM are less than $\$ 150,000$. There is as a result no need to increase the cut off amount.

A number of somewhat noteworthy suggestions from customers were posted on improving ATM service capacity (as in the installation of more ATMS), implementation of a routine maintenance policy to keep the machines functioning to provide services and the provision of a conducive environment around the ATM facility in the form of shades and waiting space.

\subsection{Cost Model for the ATM Queueing System}

We define the total cost for the ATM queuing system with S ATMs as the sum of the operating cost of running the ATMs and the wait cost as customers wait in queue. That is,

$$
T C=T C_{s}+T C_{w}
$$

Where.

$\mathrm{TC}=$ total cost for operating the ATM queuing system with S ATMs

$$
\begin{gathered}
\mathrm{TC}_{\mathrm{s}}=\text { total operating cost of S ATMs at case bank } \\
\mathrm{TC}_{\mathrm{w}}=\text { total cost of customer wait in queue }
\end{gathered}
$$

And.

$$
T C_{s}=S \times C_{S}
$$

Where $\mathrm{S}$ is the number of servers and $C_{S}$ is the cost of operating an ATM and thus may include cost of labour to fix mechanical faults, cost of labour to periodically stock the machines with cash and the cost of installation of additional ATMs. In the same way, total cost of customer wait queue at the case ATMs $\left(T C_{w}\right)$ is equal to the wait cost $\left(C_{w}\right)$ of customers in queue per unit time multiplied by the average number of customers that are present in system $\left(L_{S}\right)$ per unit time.

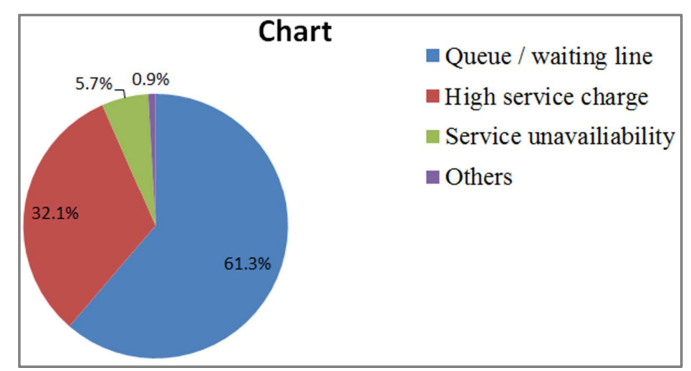

Figure 1. Customers concerns in the use of the ATM for transaction performance. 


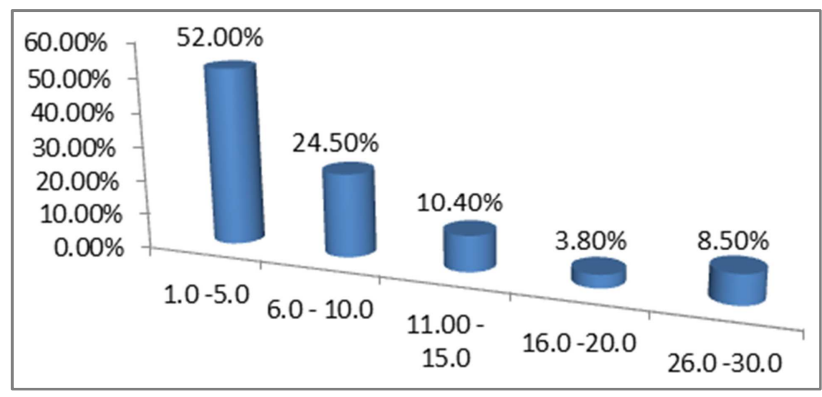

Figure 2. Customer's definition of acceptable waiting time in queue.

Wait cost may refer to the cost of losing customers (not keeping them in queue) who are unhappy and are less likely to return due to long wait in queue. The average daily cash withdrawal at the ATM if known could be used as the waiting cost - value. The total cost of customer wait in queue at the case ATMs can therefore be expressed as:

$$
T C_{w}=L_{S} \times C_{w}
$$

From equation 1.1 and 1.2 , equation 1.0 becomes.

$$
T_{C}=\left(S \times C_{s}\right)+\left(L_{S} \times C_{w}\right)
$$

Let the cost of operating an ATM at case bank is $\$ 1000$ and cost of waiting customers in queues is $\$ 1000$, then with the 2 ATMs, $T_{C}=\$ 3891.7$

Now, we want to find out if increasing the number of servers can help to reduce the amount of time spent on the queue and hence minimize the cost incurred by waiting. Hence we compare solutions.

Let $\lambda=0.1452$.

$$
\begin{gathered}
\mu=0.1205 \\
\mathrm{C}=3 \\
\frac{\lambda}{\mu}=1.2050
\end{gathered}
$$

Hence, utilization rate.

$$
\rho=\frac{\lambda}{3 \mu}=\frac{0.1452}{3(0.1205)}=0.4017
$$

Average number of customers in the queue.

$$
L_{q}=\frac{3 \rho^{4}}{1-\rho^{2}}=\frac{3(0.4017)^{4}}{1-(0.4017)^{2}}=0.0957
$$

Average number of customers in the system.

$$
L_{s}=L_{q}+\frac{\lambda}{\mu}=0.0957+1.205=1.3007
$$

Expected waiting time in queue.

$$
T_{q}=\frac{L_{q}}{\lambda}=\frac{0.0957}{0.1452}=0.6591
$$

Using equation 1.3 to find the total cost of operating the ATM yield.

$$
\begin{gathered}
T_{C}=\left(S \times C_{S}\right)+\left(L_{S} \times C_{w}\right) \\
\text { Where } \mathrm{S}=2, C_{S}=1000, L_{S}=1.3007, C_{w}=1000 . \\
\therefore T C=(2 \times 1000)+(1.3007 \times 1000) \\
=2000+1300.7=3300.7
\end{gathered}
$$

\subsection{Optimal Number of ATMs}

We define the optimal number of ATMs as the number of ATMs that ought to be set up to achieve basically two objectives of reduced customer wait time and reduce cost of providing services. The challenge therefore is determining whether or not cost would be less by maintaining current capacity. The cost values of running the system at current capacity are firstly computed. The operating cost is then determined by varying the number of ATMs. Then we assumed $C_{s}=1000$ and $C_{w}=N 1000$.

We observe that with existing capacity, the total cost of running the system is N3891.7. Customers at this level wait on average of approximately 5minutes to get chance of performing transactions. However, if an additional ATM is installed, the total operating cost of the system decreases to N3,300.7. This is N 591 less compared to when two ATMs are in operation even though waiting time in queue reduces with additional ATMs. The number of ATMs associated with the minimum total system cost is therefore three. It is evident, there is a considerable cost saving running three ATMs at current arrival rate and service rate instead of two or more than three.

Therefore, we arrive at a conclusion that the cost for operating three ATMs for this scenario is relatively cheaper while at the same time desired wait time is met. More importantly, at capacity of three ATMs, customer wait time is at a tolerable 1minute. Utilization moreover is an appreciable level of approximately $40 \%$ and diminishes unfavorable with additional ATMs. Therefore to meet demand of customers, for this scenario, three ATMs need to be set up.

\section{Conclusion}

The analysis of queueing situation in any system where it occurs is very important for the good of such system. As it concerns this case study, the evaluation or analysis of their queuing system shows that the bank needs to increase the number of their servers to 3 as shown in the result analysis. The increase in the number of servers will reduce the time customers have to wait in line before been served. This will also increase the efficiency of the bank due to the appreciation in their server to the customers as and when due. This is in tandem with the study [12] that the time of customer queuing is being reduced and customer satisfaction is increased. It was proved that this optimal model of the queuing is feasible. Results of analysis reveals that approximately ninety two percent $(92 \%)$ of respondents prefer to perform banking transactions, more specifically cash withdrawal at ATM terminal. Various and varying 
reasons are given for this preference such as ease of use, convenience and availability during weekends. Survey data however demonstrates that customers in their interaction with the ATMs are most concern about meeting a lengthy waiting line of customers.

However it was identified that service unavailability is a major problem impacting ATM usability and queue development. To curb this require rolling out some kind of a routine maintenance procedure to quickly determine and fix mechanical and other faults that might arise during the course of operation.

\section{References}

[1] Aldajani, M. A. and Alfares, H. K. (2009), Location of Banking Automatic Teller Machines Based on Convolution. System Engineering Department, King fand University of Petroleum and Minerals, Dharan 31261, Saudi Arabia.

[2] Abor J. (2005). Technology Innovations and Banking in Ghana: An Evaluation of Customers Perceptions legion. Ife Psychologia 13 (1): 170-187.

[3] Sharma A. K (2013) Advanced Numerical Modeling: University of Delhi, India.

[4] Olorunsola S. A, Adeleke R. A and Ogunlade T. O (2014) Queueing Analysis of Patient Flow in Hospital. IOSR Journal of Mathematics 10 (4): 47-53.

[5] Ogunlade Temitope Olu and Okoro Joshua Otonritse (2015) Waiting Time Analysis of A Single Server Queue in an OutPatient Clinic. IOSR Journal of Mathematics 11 (3): 54-58.

[6] Eze, E. O. and Odunukwe, A. D (2015). On Application of Queuing Models to Customers Management in Banking System. American Research Journal of Bio Sciences 1 (2): 1420.

[7] Raimi O. A. and Nenuwa I. O (2015). Queueing Model for Banking System: A Comparative Study of Selectected Banks in Ondo State Nigeria. American Journal of Engineering Research 4 (8): 191-195.
[8] Bakari H. R. Chamalwa1, H. A. and Baba A. M.(2014) Queuing Process and Its Application to Customer Service Delivery (A Case study of Fidelity Bank Plc, Maiduguri) International Journal of Mathematics and Statistics Invention. 2 (1): 14-21.

[9] Ahmed S. A. and Huda K. T. (2011) Automatic Queuing Model for Banking Application. International Journal of Advanced Computer Science and Applications. 2 (7): 11-15.

[10] Toshiba S, Sanjay K. S and Anil K. K (2013). Application Of Queuing Theory For The Improvement Of Bank Service International Journal of Advanced Computational Engineering And Networking, 1 (4): 15-18.

[11] Nityangini J. And Pravin B. (2016). Application Of Queuing Theory In Banking Sector. IOSR Journal of Mathematics 12 (2): 73-75.

[12] Xiao, $\mathrm{H}$ and Zhang $\mathrm{G}$ (2010), The Queuing Theory Application in Bank Service Optimization Proceedings of the International Conference on Logistics Systems and Intelligent Management. IEE, China.

[13] Lin, P and Yang A. S (2006). Service Efficiency Evaluation of Automatic Teller Machines: A study of Taiwan financial institutions with the application of queuing theory. Journal of Statistics and Management Systems 9 (3): 555 - 570.

[14] Vasumathi, A and Dhanavathan, P (2010) Application of Simulation Technique in Queuing Model for ATM Facility. International journal of Applied Engineering Research, Dindigul. 1 (3): 469-482.

[15] Singh, L. K and Srivastava, R (2007) "Memory Estimation of Internet Server using Queuing Theory: Comparative Study between M / G/ 1, G / M / 1 and G / G / 1 queuing model" World Academy of Science, Engineering and Technology International Journal of Mathematical and Computational Sciences (1) 9: 416-420.

[16] Hillier, F. S, \& Lieberman, S. (1974) Operation Research. S. K Jain, Inc. 